\title{
PRESENTACIÓN: \\ NOTA SOBRE MODERNIZACIÓN \\ EDUCATIVA EN LA HISTORIA \\ DE IBEROAMÉRICA
}

\section{Presentation: \\ A note on educational modernization \\ in the history of Latin America}

José María Hernández Díaz

Universidad de Salamanca

Correo-e: jmhd@usal.es

L

OS PROCESOS DE HIBRIDACIÓN cultural, étnica o religiosa representan para Iberoamérica una trayectoria de larga duración, si se nos permite utilizar la clásica expresión de Fernando Braudel, que tanta fortuna ha alcanzado en todo el mundo, y sobre todo tanta utilidad ha permitido obtener para la historiografía contemporánea.

En nuestro ámbito educativo resulta particularmente visible esa heterogeneidad de procedencias del pasado lejano, o del próximo, que nos ayudan a comprender mucho mejor los procesos de modernización educativa que se producen en los diferentes países que conforman la comunidad iberoamericana. La tradición colonial recibida de las potencias europeas en su momento, y más recientemente por medio de la presencia tan incisiva de la cultura anglosajona, versión estadounidense, forman una parte sustancial de las claves explicativas de esos procesos de modernización educativa que vive todo el continente, en particular en el siglo xx y en el actual.

Desde las antiguas metrópolis en los siglos de dominación colonial se trasladan pautas e instituciones educativas portadoras de esa ambivalencia de imposición y libertad que representa siempre la escuela, la universidad, modelos en su día foráneos y alternativos a la cultura y maneras de educar propias de los pueblos originarios. Pero muchas de aquellas prácticas educativas también representan modos de avance e innovación cultural, compatibles y coexistentes con los 
PRESENTACIÓN: NOTA SOBRE MODERNIZACIÓN EDUCATIVA

EN LA HISTORIA DE IBEROAMÉRICA

JOSÉ MARÍA HERNÁNDEZ DÍAZ

de imposición y dominio, todavía bien visibles en las pautas organizativas de los países que se han teñido culturalmente de Portugal y de España, cada uno de ellos en sus modalidades y rangos.

El factor religioso, trasladado al ámbito de lo educativo, representa una de las constantes de la educación iberoamericana antes y después del nacimiento de sus sistemas educativos. Las políticas educativas confesionales católicas (y más recientemente también de otros signos cristianos próximos), los debates sobre la laicidad de la escuela, la presencia activa de congregaciones religiosas católicas dedicadas a la enseñanza primaria y secundaria, pero también de manera muy combativa a promover instituciones propias en la educación superior y las universidades, este conjunto de factores configura un clima educativo en Iberoamérica, en el pasado próximo y en la actualidad, que hace inevitable la consideración de lo religioso en la actividad pedagógica cotidiana y en los impulsos a diferentes procesos de innovación.

En el último siglo, como bien explicaba el lúcido político de la educación e historiador argentino, e iberoamericano en todos sus costados, fallecido hace pocos meses, Juan Carlos Tedesco, América Latina gozó en varios de sus países de la oportunidad de una recepción temprana de varios de los rasgos propios del movimiento de la Escuela Nueva, desde sus dos círculos científicos principales, Chicago y Ginebra. De ahí que figuras tan señeras de este movimiento pedagógico innovador, como Adolfo Ferriére, John Dewey, entre otras, no resultaban ajenas ni desconocidas para quienes, ya antes de la Segunda Guerra Mundial, y sobre todo después de 1945, buscaban impulsar mejoras e innovaciones en los sistemas educativos de sus respectivos países. La aspiración a superar la vieja escuela tradicional e inoperante se ha erigido en una presencia constante en los movimientos de innovación educativa emergidos desde los sectores populares de toda Iberoamérica, aunque también con frecuencia forman parte de la retórica del poder que administra las decisiones políticas y reales de cambio en las escuelas iberoamericanas, en todas sus instituciones educativas.

Un factor complementario de lo dicho, pero muy determinante en países como México sobre todos los demás, resultó ser el efecto del exilio forzado de miles de educadores españoles como consecuencia de la guerra civil vivida en España desde I936 a 1939, y el posterior periodo de dictadura franquista. La llegada forzada a América Latina, a partir de I939, de un numeroso y cualificado cupo de profesores universitarios, maestros, pedagogos, inspectores de educación, técnicos culturales españoles, como contraste, enriqueció sin duda los incipientes procesos de innovación que ya se vivían en todo el continente, si bien de manera aún muy germinal. ¿Cómo podría comprenderse, por citar un solo ejemplo entre varios, el impulso a la innovación educativa en toda Iberoamérica si prescindiéramos de una figura como la de Lorenzo Luzuriaga? El exilio pedagógico que desangra España, como consecuencia de la feroz contienda ya citada, va a resultar altamente fecundo para la educación de la mayor parte de los países que conforman la comunidad iberoamericana.

Otro fenómeno, que no resulta exclusivo para la educación de los países de Iberoamérica, porque es internacional, se produce después del final de la Segunda 
Guerra Mundial, y de manera más explícita desde los años 1960 en adelante. Las tesis del capital humano, que por esas décadas hacen fortuna en la economía y en las ciencias sociales norteamericanas se trasladan con absoluta beligerancia e impunidad a los sistemas educativos del continente iberoamericano, en algunos casos apoyándose en estructuras políticas de corte militar dictatorial (Argentina, Uruguay, Chile, Brasil, Colombia, Nicaragua son suficientes para no enumerar todos los ejemplos). Tecnocracia, concesión de valor económico a la inversión en capital humano y dictadura militar conforman un sustrato imprescindible de los sistemas educativos que se desea instrumentalizar, y al mismo tiempo reconvertir en sus elementos técnicos y de política educativa. A ello se añadirá de manera persuasiva, dentro de la pretendida cultura de la eficacia y la rentabilidad, el nuevo paradigma de la calidad y de su arma de combate como es la acreditación de todos los componentes de una institución educativa o del conjunto del sistema escolar. Por ello, hay que avanzar, que los procesos derivados de la pretensión de eficacia y calidad de un sistema educativo y sus instituciones, elaborados por la materia gris de los laboratorios de Chicago o Harvard, alcanzan una presencia mucho más temprana en América Latina que en los países de la Unión Europea, como es bien sabido, y con muchas menos resistencias en su aplicación.

Por otra parte, los avances producidos durante el último siglo en al desarrollo de las ciencias, en su conjunto, y en las disciplinas escolares en particular, también han comenzado a penetrar en la investigación propia de las ciencias de la educación en toda Iberoamérica, y en su proyección innovadora en las aulas, en los centros educativos, bien sea de primaria o de educación secundaria. Se ha producido una reconocida efervescencia, en ocasiones con mucho éxito, en el movimiento innovador dentro del campo del curriculum y de las disciplinas escolares, y de sus respectivas historias, como bien explican autores como I. Goodson o A. Chervel.

De varias de estas cuestiones relacionadas con la modernización y la innovación educativa en Iberoamérica escriben los autores que firman los artículos que conforman este monográfico, y a quienes agradecemos su generosa y cualificada colaboración científica. 